\title{
A Pilot Study on the Development of the Experienced Rural Tourism in Shijiazhuang of China
}

\author{
Zhiguo Zhang \\ College of Resources and Environment Science \\ Hebei Normal University, Shijiazhuang 050016, China \\ E-mail:hbjhm@126.com \\ Tingting Yang \\ College of Resources and Environment Science \\ Hebei Normal University, Shijiazhuang 050016, China \\ E-mail: tingtingyang0109@126.com
}

Wenjie Gao

Urban and Rural Planning and Design Institute of Hebei Province

Shijiazhuang 050021, China

E-mail: hbgaowenjie@126.com

\begin{abstract}
Based on the feasibility analysis that China develops the experienced rural tourism, we analyzed the tourism resources around Shijiazhuang in this article, and divided the tourism sites around Shijiazhuang into five types. We pointed out the advantages and limited factors that Shijiazhuang developed the experienced rural tourism and respectively put forward different development advices combining with various types. We put forward the new opinion developing the experienced rural tourism to promote the new countryside building, and advised taking the development of rural tourism as the change to build the new socialist countryside.
\end{abstract}

Keywords: Shijiazhuang, Experienced rural tourism, Development

\section{To develop the experienced rural tourism can promote the building of new countryside}

The new socialist countryside should be built according to the total requirements that the production should be developed, the life should be wealthy, the rural mores should be civilized, the village appearance should be clean and the management should be democratic. That requires us to liberate our ideas, develop our thoughts, and change the concepts of growth such as letting the farmer become into a sort of vocation, not a sort of identity, letting the countryside become into a residence, not a sort of administrative district, letting the agriculture become into the industry which can be free "advance and retreat", letting farmers liberated from the land develop and build the new socialist countryside. 
The tourism is called as the "smokeless industry", and to actively develop the rural tourism can make the countryside develop only depending on its own strength, reduce national capital supports, promote the change of the rural even the national economic structure adjustment and economic growth mode, and push the "development of the production". To develop the rural tourism and emphasize the participation of the community can extend the employment of the countryside, increase farmers' incomes, enhance farmers' living level and achieve "wealthy living". To develop the rural tourism and contact exterior culture and advanced thoughts can enhance farmers' cultural level and moral quality, and promote "civilized rural mores". To develop the rural tourism can strengthen farmers' resource consciousness and environment consciousness, be propitious to protect the resources and environment and establish the society with "saving resources and friendly environment", and live up to "clean village appearance". To develop the rural tourism and quicken the exterior communication and standardize the management of tourism resource can help to realize the "democratic management". To develop the rural tourism is the important approach to promote the building of the new socialist countryside, the important means to increase incomes and become rich for farmers, the important content to implement the scientific outlook on development and establish the harmonious socialist society, and it accords with the goal and requirement of Chinese Party Central Committee to build the new socialist countryside (Zhou, 2007, P.25-28).

The development of the tourism market points out the way for the building of new countryside. As viewed from the economics, the ideal rural tourism is the combination of the tourism and the agriculture, and it is a sort of affixation under the situation that the third industry doesn't influence the first industry, and it is a sort of form that the agriculture changes to diversified operation. As viewed from the geography, the development of the rural tourism indicates that the region possesses not only the basic survival factors of the agricultural society, but the conditions developing the tourism (Wang, 1999, P.38-42). The circumjacent countryside of the big city can completely grasp the uncommon opportunity, fully dig local tourism resources and build the new socialist countryside combining with the development of the tourism.

\section{The feasibility analysis to develop the experienced rural tourism}

According to the research report of WTTC, up to 2010, the employers in Chinese tourism industry will achieve 0.19 billion, and the total income of Chinese tourism in 2020 will exceed 3300 billion Yuan which equals to $8 \%$ of Chinese GDP, and the tourism will be the mainstay industry of national economy (Hu, 2007, P.52-53).

At present, Chinese mass tourism is in the ascendant, especial for the big cities, with the quickening of the urban living, denizens' pressures are larger and larger, and along with day and night hurly in the city, denizens' desires to return the nature are more and more intensive, and with the enhancement of living level, denizens expect more and more improved living quality, and with the increase of urban population, denizen's average green area decrease sharply, and because of large work pressure, present holiday mode and economic endurance ability, most denizens select the destination of the tourism in the outskirts of the city. Mr. Wu Bihu called this tourism range as the "recreational belt around metropolis (ReBAM)" (Wu, 2001, P.354-359).

\section{Analysis of the rural tourism belt of Shijiazhuang}

There are 5 cities, 6 districts and 12 counties in Shijiazhuang which total area is 14161 square kilometers, and it has 9555 thousands permanent population, and the urban area is 453.6 square kilometers, and the urban population is 2377.3 thousands, and the population density is 5241 person per square kilometer. In 2007, the regional production gross was 239.3 billions Yuan, and the urban per capita disposable income was 13.205 thousands Yuan, and the urban per capita consumption payout was 9189 Yuan.

\subsection{Definition of the rural tourism belt of Shijiazhuang}

Wu Bihua, Huang Zhuowei and Ma Xiaomeng (2004) researched and found that the distribution of rural 
tourism area around the big and middle-sized cities presented the decreasing trend with the distance (except for the initiatory 30 kilometers), and $84 \%$ of tourism areas were centralized in the range which distanced the city in 100 kilometers ( $\mathrm{Wu}, 2001$, P.757-763). Considering that the modern traffic develops very quickly, and the public traffic advances rapidly, and various counties in Shijiazhuang can be arrived in 3 hours, and large amounts of private car largely promote the urban and rural association and reduce the time distance between the city and the village, in the article, we define the rural tourism belt of Shijiazhuang in the range which can be arrived by the public traffic in 3 hours, and the range includes the counties around Shijiazhuang, the Dingzhou City in the north of Shijiazhuang and the Lincheng County in the south of Shijiazhuang.

\subsection{Experienced tourism resources evaluation of Shijiazhuang rural tourism}

For the problem what is the "rural tourism", there are many definitions such as the rural tourism, the rural experienced tourism, the rural participated tourism, the agriculture of going sightseeing, the leisure agriculture and the agricultural tourism in the academe. Zheng Liaoji (Zheng, 2006, P.118-125), Zheng Qunming, Zhong Linsheng (Zheng, 2004, P.33-37), and He Xiaorong (He, 2004, P.90-94) had made relative researches. The "experienced rural tourism" in this article means to take the residents in the central city as the main passenger source based on special rural natural and human landscapes, take the keeping of rural scene and land flirtatious expressions as the characters, take hobnobbing with the nature and feeling the land as the core, feel the natural mountains and rivers, accept real farmhouses to fulfill tourists' goals relaxing emotion, reviving pressure, returning nature and feeling themselves. At the same time, the countryside should strengthen the construction of the basic establishment and develop the special commodities to fulfill tourists' integrated demands including food, house, travel, visit, amusement and purchase. The experienced rural tourism possesses many characters such as practice, experience, amusement, education and relatively destroying.

\subsubsection{Experienced tourism resources division of the local rural tourism belt}

The tourism resources of the rural tourism belt in Shijiazhuang are abundant, and they can be divided into following types according to the attributes and characters.

(1) The mountains and rivers type. The representative scenery spots include Mountain Cangyan, Wuyue Village National Forest Park, Zhangshiyan National Geopark, Baodu Village, Pingshan Tuoliang Mountain, Mountain Tiangui, Kongshan Baiyundong National Park.

(2) The historical cultural type. The representative scenery spots include the famous historical and cultural city of Zhengding, the famous historical and cultural city of Zhaoxian, the Tianchang ancient town in Jingxing County, Yujia Stone Village, the ancient village group of Daliang River, Zhongshan County in Pingshan County.

(3) The folk-custom and special local product type. The representative products include Jingxing Lahua, Zhengding Civil Flower Meet, Snowflake Pear of Zhao County and Chinese data of Zanhuang.

(4) The revolution sacred place type. The representative place is the Xibaipo in Pingshan County.

(5) The ecological civilization type. The representative spots are numerous ecological demonstration villages.

\subsubsection{Advantage of comparison}

The urban population of Shijiazhuang had exceeded 2300 thousands in 2007, and the population density had exceeded 5000 persons per square kilometers, and the urban per capita disposable income had broken 13 thousands Yuan, and people have the desires and financial ability for trip.

The citizens' recreational demands of Shiajiazhuang are very intensive, and most citizens have participated into the outing, and they could complete the trip in the present day or two-day holiday basically (Jia, 2002, P.84-89). 
Comparing with the urban districts, the circumjacent scenery spot in the rural tourism belt possesses following obvious advantages.

(1) The rural regions without the hurly of the big city are closed to the nature.

Urbanites have been bored by the boisterous environment for a long time, and in the countryside, they can approach the land and the nature, "while picking asters neath the Eastern fence, my gaze upon the Southern mountain rests", and they can really taste the coziness of "being in the bird cage for a long time, returning to the nature again".

(2) The tourism resources in the rural regions are abundant, and the varieties are numerous and the area is wide.

The countryside possesses wide sky and land, and there are not only the natural scene, but also human sceneries, and people can not only enjoy the mountains and rivers, but also accept the patriotic education, and they can not only feel the uncanny workmanship of the nature, but also take the great pioneering work of the people, wander in the farms, appreciate the nature, feel themselves, learn knowledge, widen the view, forget the worry and feel the happiness, and benefit the life and health.

(3) The values of the tourism resources in the rural regions are very high.

Many scenery spots such as the Mountain Cangyan, Zhangshiyan National Geopark, Kongshan Baiyundong National Park and Mountain Tiangui are national class tourism scenery spots, and especially the Karst landform possesses obviously special characteristic and rarity characteristic. Xibaipo is the famous patriotic education base, one of six sacred places of the revolution, and it can make people really fell "the first sun rays in the morning of new China".

(4) The combination status of the rural tourism resources is better.

Many scenery spots are neighboring each other, and the combination of the sceneries is better, and the further organization can produce the effect of " $1+1>2$ ". For example, the scenery spot of Xibaipo is closed to the Gangnan Reservoir, and the distance between it with the famous scenery, Mountain Tiangui is only 40 kilometers, and the distance between it with the onetime capital site of Zhongshan County about 45 kilometers, and the distance between it with "First Village under Heaven", Baodu Village, is 90 kilometers, and the distance between it with the Buddhism scared place Wutai Mountain is 120 kilometers.

\subsubsection{Limited factors}

(1) The regions of the rural tourism lack in uniform layout, the sceneries are identical and the competition is graved.

The rural tourism regions lack in uniform layout. First, the sceneries in various tourism regions are identical, for example, when the picking rises, many villages will develop the "picking festival", and the blind imitation and competition destroy the good combination of the tourism resources, which make the scenery become humdrum, and visitors will be bored. Second, the interiors of many tourism regions lack in programming, and the living is sluttish and the village appearance is worm-eaten, which will induce the rural tourism lack in attractions.

(2) The rural infrastructure construction is deficient and the environment should be further improved.

First, the traffic is not convenient, and the roads toward various rural tourism spots are bad and the standard is very low. Second, the traffic connections among various neighboring rural tourism spots are bad. Third, the reception establishments in some rural tourism spots are much undeveloped. The bad environment and imperfect infrastructure largely influence the entrance of visitors, and strike visitors' desires to visit. 
(3) The development deepness of the rural tourism resources is not enough, and the layer is not high, and the complete industrial chain has not been formed.

Wang Bing (Wang, 1999, P.79) pointed out that Chinese rural tourism presented large dependence for the tourism scenery spot, the harvest activity of the agricultural production and the traditional festival. Chinese rural tourism still stays in the layers of visiting, picking, chatting and wandering in the farms, and it lacks in the embodiment of the folk cultures, and the development deepness is not enough, and the layer is not high, and the independent tourism cultural industry chain has not been formed. The deficient innovation design, deep processing and cultural meanings can not make tourists experience the local folk custom, which will influence the attraction of the tourism products and the revisiting rate.

(4) The traditional scenes in the historical and cultural districts should be protected early, and the balance should be looked for in the relation between the protection and the development utilization.

Different problems exist in the historical and cultural districts, and the protective consciousness becomes indifferent, and the property of construction is largely destroyed, and many buildings lack in repairs for long. Most historical streets have not been programmed and protected. Historical buildings and environment has been destroyed to different extents. The thought of protecting the culture has not gone deep into human hearts, and common villagers have not completely known the resources what they have. The construction skills and technologies of the old buildings are disappearing, and they are urgent to be saved and protected, for example, the horizon contour line of the historical city, Zhengding, has been and will be destroyed to some extent.

(5) The production scale of the tourism products is small, and the sales can not form the system.

The commercial consciousness is lagged, and the tourism commodity with local characteristics can not be developed, and the sales of the commodities lack in independent network system.

\section{Development advices for Shijiazhuang rural tourism belt}

4.1 Increasing the power of environment protection, and further developing the beauty spot tourism resource with mountains and rivers

For the scenery spots with mountains and rivers, people want to experience their natural characters, so we should not be adsorbed in the front benefits, but ignore the environment protection and make the beautiful mountains and rivers become bare mountains and dangerous rivers. The villages near the scenery spots should constantly emphasize the environment protection, and protect the environment that people depend on. Based on the environment protection, rebuild the new countryside, strengthen the infrastructure construction, increase the production of special commodities, and provide multiple services such as eating, housing, buying and traveling for visitors. Before the construction, the layout should be made better, and the construction can not destroy the environment of the scenery spot. We should strengthen the traffic association between the villages and scenery spots, and strengthen the traffic association between the villages and the visitor sources, and the villages should be the middle station between the visitor sources and the scenery spots to server for the recreational activities.

\subsection{Reasonably designing the layout and instructing the protection of historical and cultural streets and districts}

For the resources in the historical and cultural conservation districts, we should scientifically make the layout, reasonably utilize them, and fully dig their social values such as history, culture, scientific technology, arts, education, nationality and tourism, and emphasize the survival environment of the historical and cultural conservation districts, and give prominence to the "historical reality, life reality and shape integrity". Better grasp the renovation contents of the historical and cultural conservation districts, avoid dismantling and 
building randomly by all means, live up to save the appearances and "repair as old", renovate the interior to fulfill citizens' living and inhabiting demands.

Using international modus for references, the better historical buildings in the historical and cultural conservation district should be reserved, the disrepair building can be repaired, and the ratty buildings can be dismantled and rebuilt by the original appearance. We should save the original parts of the historical buildings to the largest extents, and reflect the traceability and the identification of the historical buildings (Cui, 2005).

\subsection{Inheriting the folk-custom culture and promoting the spread of special rural culture}

The rural tourism can not stay in the layers of viewing, picking, chatting and wandering in the farms only, but should fully dig the meaning of the folk-custom culture, enhance the class, increase the development depth, find the abundant nourishments in the national culture, fully dig the profound connotations in many aspects such as cultural tradition, national custom, manners and customs, local folk art forms, civil craftworks, festival activity and industrial culture, embody the characteristic of Taihang Mountains and the flirtatious expressions of Yan Country and Zhao Country, and form the tourism cultural industry chain. The rural tourism should also fully dig the experienced contents, go on the road of commercial operation, pass the civilization, and benefit the local countryside.

\subsection{Carrying forward revolutionary spirit and promoting the development of red tourism areas}

In the development of the rural experienced tourism, combining with the patriotic education, advocate the green scenes, blue waters, historic sites, new appearance of villages and cultural meanings, and strengthen the comprehensive development degree of the tourism resources, and let tourists rememorize the red history and appreciate the village expressions and fulfill their multiple demands.

\subsection{Relying on the engineering of water diversion and driving the rural ecological construction along the line}

The midline and trunk line engineering of South-to-North water diversion passes Shijiazhuang. The villages along the water diversion engineering can take the opportunity of this engineering to rebuild the dwellings, deal with the dwelling houses exceeding the standard and the leisure house sites, make the second working, and enhance the infield quality under the premise that the gross of the infield doesn't decrease, build the dwellings with simple and unsophisticated appearance and modern interior establishment, and construct the beautiful human settlement.

In the rebuilding process of villages, the establishment of the civilized ecological village should be the goal, and according to the total requirement of "developing economy, healthy democracy, enriched spirit and better environment", strengthen the rural infrastructure construction and the building of the courtyard and environment. Start from rigidifying the road surface, cleansing the streets and courtyard and planting in the village, and strengthen the constructions of many suited establishments such as the drinking security, garbage disposal and street illumination, and achieve the goal of "improving a batch", and really profit people.

The places along the line which can develop the tourism industry should properly develop the construction of the tourism scenes. Pay attention to the combination of the landform with the water flow, adjust measures to local conditions, build the scenery spot by the water, and fully reasonably utilize the limited water resources under the deficient water environment. Define the programming construction region, advocate all citizens to take part in the construction, and offer saplings and grass seeds to plant for tourists.

\subsection{Strengthening the consciousness of commodity and fulfilling tourists'various demands}

Villagers leaded by the village committee and the branch committee of CPC should strengthen the degree of the commercial operation, produce special tourism commodities, let tourism consumers buy the tourism products in the usual farmer homes, and make the tourists' demands including food, house, travel, visit, 
amusement and purchase fulfilled in the common farmers' homes.

4.7 Strengthening the cooperation and digging the self characteristic to realize the mutual benefit and win-win

The cut-throat competition among various scenery spots, especially among the scenery spots with close geographical positions should be avoided. Every scenery spot should preserve the whole benefits, and the consultation mechanism and the linkage mechanism should be established, and all scenery spots should be as a whole, and every scenery spot develops his project with the best advantage, which can realize the mutual benefit and win-win and achieve the profit maximization.

\section{References}

Cui, Jianfu, Baolong, Gao, Wenjie \& Xing, Tianhe. (2005). Research of the Protection for the Famous Historic and Cultural City and the Conservation of Historic Sites in Hebei Province (first edition). Beijing: China Press of Science and Technology. Oct, 2005.

He, Xiaorong. (2004). Study on the Origination, Actuality and Development Trend of Chinese Rural Tourism. Beijing Second Foreign Language Institute Journal. No. 1. P.90-94.

$\mathrm{Hu}$, Tiancui. (2007). Analysis of the Tourism Industry on Economic Growth Overflow Effect. Co-operative Economy \& Science. No. 316. P.52-53.

Jia, Liming, Chen, Xinfeng \& Liu, Zeliang et al. (2002). A Pilot Study on the Outdoor Recreation Demands of the Citizens in the Chief Cities Around Taihang Mountain. Journal of Beijing Forestry University (Social Sciences). No. 2/3. P. 84-89.

Wang, Bing. (1999). Looking the Future of Chinese Rural Village from the Comparison of Foreign and Domestic Rural Tourism Actualities. Tourism Tribune. No. 2. P. 38-42, 79.

$\mathrm{Wu}$, Bihu. (2001). A Study on Recreational Belt around Metropolis (ReBAM): Shanghai Case. Scientia Geographica Sinica. No. 21(4). P. 354-359.

$\mathrm{Wu}$, Bihu, Huang, Zhuowei \& Ma, Xiaomeng. (2001). Spatial Structure of Rural Tourism Attractions in Suburban Areas of China. Scientia Geographica Sinica. No. 24(6). P. 757-763.

Zheng, Liaoji. (2006). Research on the Experiential Tourism of Rural Area in Eastern of Liaoning Province. Ecological Economy. No. 6. P. 118-125.

Zheng, Qunming \& Zhong, Linsheng. (2004). A Discussion of Developing Model of Community-Involved Rural Tourism. Tourism Tribune. No.19(4). P. 33-37.

Zhou, Jun. (2007). Reflection on Country Tourism and Construction of Socialism New Countryside: Having Yunshe Village as Example Which Located at Jiangkou County in Guizhou Province. Journal of South-central University for Nationalities (Humanities and Social Science). No. 2. P. 25-28. 